\title{
In Situ UHV-TEM Studies of Initial Stage Cu-Ni Alloy Oxidation
}

\author{
Yihong Kang,* Judith C. Yang, ** \\ * Mechanical Engineering and Materials Science, University of Pittsburgh, Pittsburgh, PA 15261 \\ ** Chemical and Petroleum Engineering, University of Pittsburgh, Pittsburgh, PA 15261
}

The fundamental understanding of oxidation at the nanoscale is of increasing importance for both the environmental stability of nanodevices as well as the processing of functional oxide nanostructures. All classical oxidation theories assume a uniform growing film, where structural changes are not considered due to previous experimental difficulties on visualizing the structural changes at the nanoscale. Recent surface science studies have elucidated the complex mechanisms of oxygen on metal surfaces, but focuses on at most a few monolayers. The purpose of this work is to bridge the gap between surface science studies and bulk oxidation studies, which encompasses the nucleation and growth of the oxide.

We are using environmental ultra-high vacuum transmission electron microscopy (UHV-TEM) and high resolution TEM to study detailed oxidation processes at the nanoscale. Previous studies show the epitaxial growth of $\mathrm{Cu}_{2} \mathrm{O}$ islands during the initial stages of oxidation for $\mathrm{Cu}(100)$. Here surface diffusion and strain impact the morphology of oxides [1-4]. The addition of secondary elements can change the oxidation mechanism and the evolution of the oxide morphologies. If the secondary element is non-oxidizing, such as $\mathrm{Au}$, it will limit the $\mathrm{Cu}_{2} \mathrm{O}$ island growth due to the depletion of $\mathrm{Cu}$ near the oxide islands that significantly slow down the oxide growth and also lead to an unusual dendritic shape, limiting its ability to form a uniform protective oxide $[\underline{5}, \underline{6}]$. On the other hand, when the secondary element is oxidizing, for example $\mathrm{Ni}$, the alloy will show more complex behavior, where duplex oxide islands were reported [7].

In this research, the initial stage oxidation of single crystal $\mathrm{Cu}-\mathrm{Ni}$ (100) films, which are formed via UHV e-beam evaporation, is observed under various temperatures and oxygen pressures $\left(\mathrm{pO}_{2}\right)$. Nucleation density and growth rate of oxide islands formed on $\mathrm{Cu}-\mathrm{Ni}$ thin film will be studied as a function of time, and compared with pure $\mathrm{Cu}$ and $\mathrm{Cu}-\mathrm{Au}$ alloys. According to thermodynamics and kinetics, at lower temperatures and $\mathrm{pO}_{2}$ only $\mathrm{NiO}$ islands form due to oxidation of $\mathrm{Cu}-\mathrm{Ni}$. As the temperature and $\mathrm{pO}_{2}$ increase, $\mathrm{Cu}_{2} \mathrm{O}$ islands may nucleate and grow. These experiments were carried out in a modified JEOL 200CX TEM. This microscope is equipped with an ultra-high vacuum (UHV) chamber with base pressure $\sim 10^{-9}$ Torr. A specially prepared top-entry sample holder allows for resistive heating to a maximum temperature of $1000^{\circ} \mathrm{C}$. A controlled leak valve attached to the column permits the introduction of gases into the microscope up to $5 \times 10^{-4}$ Torr, thus allowing us to observe the nanoscale oxidation processes.

Initial experiments reveal that a small amount of $\mathrm{Ni}$ additions to the $\mathrm{Cu}$ will result in dramatic changes of the oxidation behavior. A rapid nucleation followed by growth of oxide islands were observed, thereby supporting an oxygen surface diffusion model. A variety of shapes of oxide islands were observed under different oxidation conditions, such as rod shape and polygon. The orientation of the oxide will also change from cube-on-cube formation to multiple orientations, ending in polycrystalline. The morphology and orientation of oxide islands will also be studied as functions of alloy composition, temperature and $\mathrm{pO}_{2}$. High resolution analytical TEM will be 
used to reveal the composition of oxide islands and the metal composition near the oxide islands after the oxidation procedure which will provide insights on the nano-oxidation mechanisms.

\section{References}

[1] G. Zhou and J. C. Yang, Applied Surface Science 210 (2003) 165.

[2] G. Zhou and J. C. Yang, Physical Review Letters 89 (2002) 106101.

[3] G. Zhou, L. Wang, and J. C. Yang, Journal of Applied Physics 97 (2005) 063509.

[4] G. Zhou, W. Slaughter, and J. Yang, Physical Review Letters 94 (2005) 246101.

[5] G. W. Zhou, L. Wang, R. C. Birtcher, P. M. Baldo, J. E. Pearson, J. C. Yang, and J. A. Eastman, Physical Review Letters 96 (2006) 226108.

[6] G. W. Zhou, J. A. Eastman, R. C. Birtcher, P. M. Baldo, J. E. Pearson, L. J. Thompson, L. Wang, and J. C. Yang, Journal of Applied Physics 101 (2007) 033521.

[7] G. Zhou, D. D. Fong, L. Wang, P. H. Fuoss, P. M. Baldo, L. J. Thompson, and J. A. Eastman, Physical Review B 80 (2009) 134106.

[8] This research was supported by the National Science Foundation (\#0523205). The aid of Matthew France of University of Pittsburgh is gratefully acknowledged.
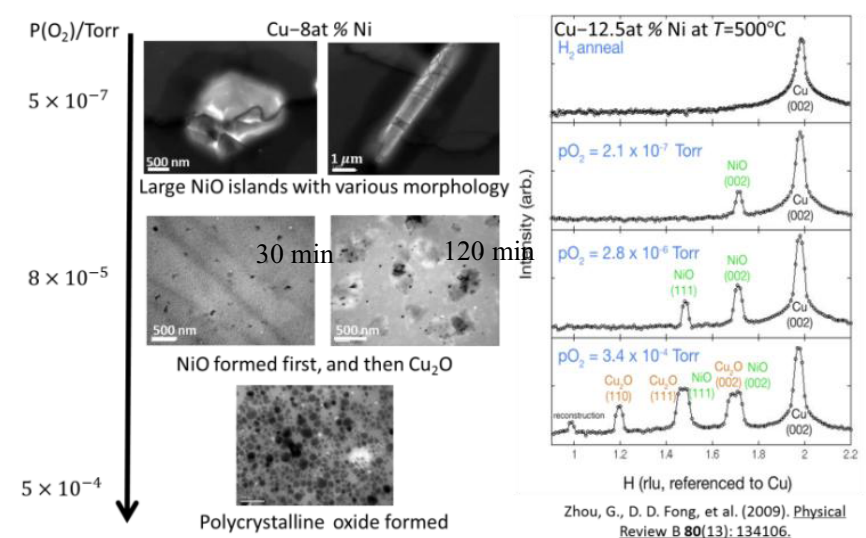

FIG. 1. $\mathrm{pO}_{2}$ dependence of $\mathrm{Cu}-\mathrm{Ni}$ alloy oxidation. Left side is TEM observation of oxide islands morphology change due to the change of $\mathrm{pO}_{2}$, right side is synchrotron XRD data of oxide type and orientation change due to the change of $\mathrm{pO}_{2}$ []].
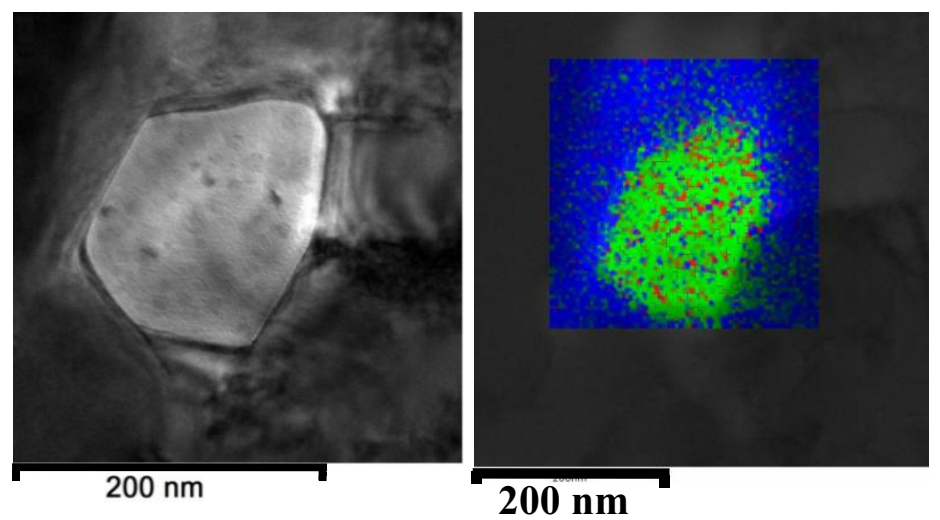

FIG. 2. EDS mapping of oxide island. Left side is the TEM image of oxide, right side is EDS mapping of $\mathrm{Cu}, \mathrm{Ni}$ and $\mathrm{O}$, where blue is $\mathrm{Cu}$, green is $\mathrm{Ni}$, and red is Oxygen. 